\title{
TRIANGULAR PYRAMID TRUNK: THE THREE AXES OF THE SMART CITY ASSESSMENT TOOL
}

\author{
DIOGO CORREIA, LEONOR TEIXEIRA \& JOÃO MARQUES \\ University of Aveiro, Portugal
}

\begin{abstract}
Smart Cities have changed from a purely technological paradigm to a holistic, integrated strategy, where the citizens play an important role in the decision-making process. Cities begin to understand the potential of integration approaches, interoperability of solutions, and start seeking strategic thinking when addressing new technologies. In this context, to implement a holistic strategy, city decision makers must have a tool that helps them to strategize according to their current state and then understand whether the actions they adopted are having the desired outcomes concerning their previously established objectives. It is not possible to create strategic visions for Smart Cities without a tool to regularly assess and monitor them. In this matter, several studies report some attempts to formulate a methodology to calculate indexes to evaluate cities' maturity level. However, they have either not taken properly into consideration indicators' weighting or the focus of the index was not clear and mixed up the key performance indicators (KPIs) of different concepts in an attempt to provide a more generic tool. Despite this, the previous studies are used as the basis to support the methodological approach of this research. This article tackles this gap in the literature by providing the most up to date Smart City assessment tool to evaluate cities. While the Smart City concept has different understandings among researchers and academia practitioners, the evolution of the concept has tended to incorporate the axes of sustainability, innovation, and quality of life. Therefore, these are featured in the present index calculation supported by the ICTs and participatory approaches. Existing standard KPIs and frameworks do not include them, focusing most of the time in one of these axes while leaving the others aside. Thus, this paper proposes to describe the development of a methodology that encompasses every one of these three axes to give cities a tool they can use to monitor their actions.
\end{abstract}

Keywords: Smart City, framework; index, participatory development, indicator, assessment, innovation, sustainability, inclusiveness, quality of life.

\section{INTRODUCTION}

Smart is not a consensual term, and what may be Smart for some may be not for the others. The Smart City is a concept that, given its nature of qualitative and at the same time distinct quantitative method evaluation, has not generated consensus in its understanding, sometimes leading cities to completely different approaches and with different ways of assessing their evolution.

The Smart Cities expression emerged in the 1990s [1]-[3] and since the first moment was seen as the solution to address rapid urbanization and urban agglomeration, solving traffic, waste management, air quality, social pressure and inequality, economic speculation and inefficiency of emergency bodies [4], [5]. Information and communication technologies (ICTs) are increasingly used as tools in the governance and management of cities to promote the integration of the several domains, improve quality of life, achieve sustainable development, and create a more open and innovative urban environment through the participation of the stakeholders [6].

Although there is not yet a widely adopted and precise definition, the Smart Cities concept has been evolving since the first techno-centric understanding [7], [8] mainly promoted by technological companies that ICTs would be the solution for everything, to a more human and sustainable point of view where the solutions sought to solve specific citizens' problems [9]-[11]. Nowadays, citizens are seen as part of the process and not just the "customer" of it. 
Their participation and involvement in the co-design and co-creation of projects and policies is fundamental to support decision-making processes [12], making sure that the solutions will be adopted when implemented [13].

After the implementation of the first projects and the attempt of some authors to establish indicators to assess Smart Cities, being the European Smart Cities Ranking [14] the most quoted and used, nearly five years ago there was noticed in the literature a lack of sustainable development in the existing tools to assess the achievement of medium or long term goals [15]. Before knowing what to do and how to do it is necessary to evaluate the situation to understand what the city's current state is. Only this way, it will be possible to define standardized procedures in order to cities can make their decisions based on quality data. The success of Smart City initiatives is related to the quality of the data collected and the key performance indicators and tools used to monitor them continually [16].

There is not yet an accepted standard assessment tool to monitor cities among researchers. Therefore, cities have been selecting the tools from themselves. Because there are dozens of rankings available in the literature and those, need expert analysis to be adequately used, it turns this city's task even harder. This choice has extreme importance since it affects city management and decision making directly [17].

While the literature shows a diversity of Smart City indexes [9], what was happening was that the tools were being created for a limited number of cities, and the focus of the indicators was utterly undefined. In particular, it was noticed the lack of ICT enabled-indicators [18] as well as a confusion generated between the Smart City concept and Sustainable City understandings which caused that many of the Smart City tools defined focused too much on the sustainability component, particularly on social and economic issues [19] while the indicators for sustainable cities placed more emphasis on the environmental component [20]. There was also a lack of an assessment tool to measure how smartness enhances sustainability and vice versa [9].

There has been noticed a notorious work at the level of some entities, such as ISO (International Organization for Standardization) and ITU (International Telecommunication Union), which have played a leading role in establishing indexes with indicators that try to align what is the sustainability of the city with the role of the new ICT [21]. However, on one hand, there is a lack of a practical component because there are no indicators that take into account the objectives of cities and the monitoring of the city's progress [22] and on the other hand indicators are not normalized either given different weights according to its importance for the index's estimation which also creates difficulties to provide cities an efficient tool [7].

\section{THEORETICAL BACKGROUND}

Following an exploratory and unstructured approach, it was conducted a research in the literature through Scopus and the Web of Science using the combination of the following key-terms: "smart cities"; "indicator"; "ranking" and "index". More than 600 papers resulted from the search. From those, it was read the 300 most cited abstracts, where 130 of them deserved a more-in-depth analysis due to their alignment with the objective of this paper and contribution to the discussion of what has been done to evaluate Smart Cities and how can that be improved.

Based on this literature review it was concluded that, throughout the years, more than 50 assessment tools were developed to evaluate cities. The conclusions of four of the comparison studies which analyse a significant number of those assessment tools are here exploited to help find a standard and common methodology to assess cities.

Thus, Sharifi [23] selects and analyses 34 sets of Smart City assessment tools. The study concludes that IES-City, SCC, CITYkeys, and ITU-T cover a "large part" of all indicators 
considered, but it is still less than 50\%. Most of them have not developed participatory approaches and there is a lack of strategic planning among the tools. Additionally, they do not consider local needs and conditions and there is a limited consideration of interlinkages and correlations among indicators, dimensions, and sub-dimensions. Flexibility is low, feasibility is not considered and don't have a continuous assessment approach.

Ahvenniemi et al. [7] analyses 16 sets of city assessment tools (eight Smart City and eight whose focus is on urban sustainability). Weighting was not considered in the study because weights were not part of most of the tools analysed. The authors conclude that the Smart City tools are highly focused on social aspects, whereas economic and environmental issues are considered less critical. On the other hand, the urban sustainability ones cover mostly the environmental and social dimensions, whereas indicators measuring economic sustainability are minimum.

Huovila et al. [21] presents a comparison of seven sets of assessment for "Smart sustainable cities" and notice that $90 \%$ of ISO 37120 and UN SDG 11+ indicators focus on sustainability and that the ITU 4902 assessment tool is the most focused on smartness and the one which has the most impact-oriented indicators.

Finally, Stratigea et al. [24] takes into consideration five city assessment tools and conclude that ICT-enabled indicators are not always presented in the comparing tools and some of them have an inadequate share of indicators assessing the smartness efforts of a city. Additionally, ITU-T has a purely ICT-enabled indicator orientation. The merging task that is done permits a more widely differentiated mix of smart and sustainable indicators.

Although there is not a size to fit in all Smart City models [25], a difference in the focus of each of the used tools should be made. Otherwise, we would be mixing concepts and obtaining ultimately decontextualized results from reality. Although one of the goals of Smart Cities is to improve sustainability with the help of technologies, we cannot misunderstand concepts and merge them as it is proposed by Stratigea et al. [24].

The conclusions of the previous studies' results raise concerns about the validity of the tools considered to assess Smart Cities. The cause could also be the fact of using the same criteria to compare assessment tools that have different goals. Given the evolution of the concept and the trend towards sustainability, it obtained the derivation of "Smart Sustainable Cities" [9], [26]-[29]. This fact contributed to the merge between indicators of evaluation [24] of a concept that points to the short term (Smart Cities) and another to the long term (Sustainable Cities) turning the focus and study of the different concepts extremely confused.

Additionally, Akande et al. [30] points as gaps:

1. Lack of a proper definition of a ranking focus and the misunderstood of concepts;

2. Lack of homogeneity (regarding city's population density, economic character, wealth, climate and history) among the selected ranked cities;

3. Unreliable data sourcing;

4. Weighting without considering the interrelationship between indicators.

Sustainability is oriented to a global approach, and it can be measured the same way for every city. However, the same cannot be applied to Smart Cities since it is somehow a local strategy that needs the inputs of local stakeholders to align the short-term actions. Along the same line, the alignment between Sustainable Development Goals (SDG) targets and indicators to evaluate actions at local scale remains unclear [31].

Therefore, it is needed a tool with an eye on the short term, monitoring if the results of the actions planned are aligned with the established goals. 


\section{THE TRIANGULAR PYRAMID TRUNK}

Towards the conclusions of the studies previously highlighted is of relevant importance to develop a methodology that approximates these tools to the strategic axes of a Smart City. Most of the assessment tools has not participatory approaches (do not include the citizen in the creation process) and do not consider local needs and conditions [23], ICT-enabled indicators are not always present [24].

The proposed model, beyond the calculation of a Smart City assessment tool, the objective will be to design a methodology capable of adapting itself with the evaluation of times and not become obsolete.

Only recently, standardized sets of city indicators have been introduced. This international standardization work has been being mostly carried out in the last years by three bodies, i.e., ISO and ITU worldwide and by the coalition of the European standardization organizations CEN, CENELEC, and by ETSI in Europe [21].

Some of the international standardization bodies have recently published six sets of Smart and Sustainable City indicators [32]-[37]. The six were compared along with the Sustainable Development Goal 11+ monitoring framework, and it is stated in the conclusions above that ISO 37120, and UN SDG 11+ indicators are the sets of indicators more appropriate to measure sustainability while ITU 4902 is the most focused on smartness.

Venkat Redy et al. [38] defines three Smart City goals:

1. Achieve a sustainable development;

2. Increase the quality of life of its citizens;

3. Improve the efficiency of the existing and new infrastructure.

On the other hand, Etezadzadeh [39] defines as Smart City goals: the preservation of the environment, maintain the quality of life and promote social development, maintain competitiveness and promote economic development and generalization of attitudes, decisions, and actions.

Sustainability and quality of life are agreed goals. The efficiency of processes is not just based on existing infrastructure or have new infrastructure implemented. There are many ways to gather real-time data without having to invest in infrastructure. Moreover, the best way to maintain competitiveness and grow is by creating and investing in innovative processes. Thus, the third goal of Smart Cities must be innovation. Innovation will always be the engine to pursuit new technologies and methodologies. Innovation could be the basis of a Smart City, however, throughout the years, we have been noticing that not even all reasonable solutions or best practices come from disruptive technology. Sometimes it is a matter of simplifying things and optimize processes. The innovation is stated here as a way of thinking, that cities must take into account.

On the same line, Barrionuevo et al. [40] defines four Smart City axes: sustainability, social cohesion, innovation, and connectivity (which should already be intrinsic in the innovation axis).

Taking into consideration all the enunciated aspects and the foundations reported in the exploratory literature review, this study defines three Smart Cities axes/dimensions supported by the ICTs and the participation of citizens and the stakeholders with the aim of promoting a Smart City that does not let anyone aside (Fig. 1). A city from all to all.

Thus, at the basis of the pyramid we can evaluate the smartness adapting to this study the thoughts of Debnath et al. [41]. We may then consider a ranking with 4 levels depending on the capacity to gather data and prevent occurrences with it, where: 


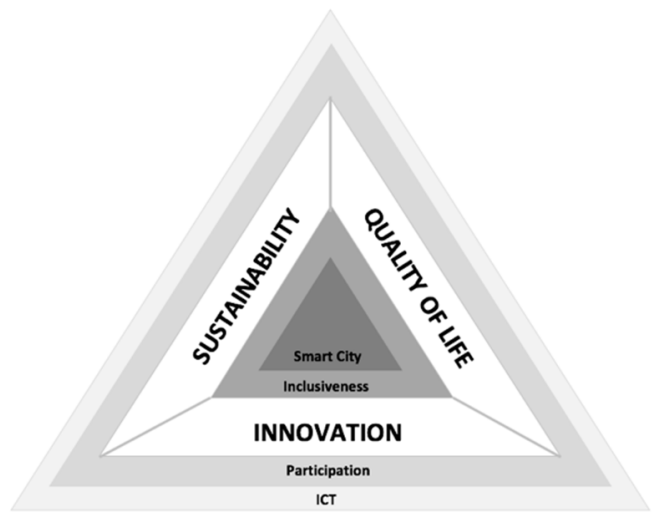

Figure 1: The Triangular Pyramid Trunk: The three Smart City axes.

1. Offline - not capable of collecting data in real-time;

2. Real Time - collects data in real-time;

3. Predicting - an advance of a potential problem with the real-time data collected;

4. Preventing - evaluation of scenarios and avoidance of occurrences.

\subsection{Sustainability}

In the 1990s started to be done urban monitoring with the establishment of the Local Agenda 21 [42], but only ten years ago were associated indicators to monitor sustainability [16]. In 2015, the United Nations developed the 17 Sustainable Development Goals (SDGs) [43]. There was a need to contextualize, align indicators with the SDGs promoting interlinkage among indicators and avoid overlapping of goals and targets [44]. According to [45], the practicability of the Smart City concept can help cities reach UN goals.

Public administration has been increasingly using urban sustainable development indicators to assess and monitor their activities [46]. The most common assessment tool used to guide them is ISO 37120 [47]. Therefore and alongside with the conclusions of [21], we will use the ISO 37120 to measure sustainability.

\subsection{Innovation}

When researchers investigated sustainability in Smart Cities was missing a focus on ICT [48]. Therefore, it is relevant to study innovation as a separate vertical. The innovation goals are supported by the real-time data that is gathered through online (and offline) tools that permit city decision-makers to make their decisions according to that information. Innovation can be mostly measured by the capacity of the city to collect data and make it available as fast as possible to decision-makers

Innovation is understood as an urban smartness technological driver [49]. Huovila et al. [21], and Stratigea et al. [24] point the ITU 4902 standard assessment tool as the most suitable to evaluate the smartness. Conducting a deep analysis, it is possible to notice that in a total of 37 indicators only eight of them are not marked as ICT-specific indicators but indicators focusing on general city sustainability, therefore we shall not consider these and associate the 80 general indicators from the Global Innovation Index [50] or other set of indicators focused on innovation aspects. 


\subsection{Quality of life}

On the other hand, sometimes the city's sustainability is misunderstood with the improvement of the quality of life of its citizens.

The concept has been worthying the attention not only of the academic community but also of policymakers. There is not yet a single, universal and consensual definition of quality of life given the fact that this is a complex, dynamic and multidimensional concept.

Quality of life was initiated by Mercer's annual quality of life survey and the Economist Intelligence Unit's quality of life index [7]. In both cases, data is collected from two different sources: life-satisfaction surveys (to get a subjective view of a population's emotional wellbeing) of citizens and quality of life indicators (objective evaluation) [16].

Each one of the axes ends up, first of all, having a normative, top-down approach, where there is a selection of KPIs ideal for the classification of that axis, and a quantitative primary analysis is made. Additionally, it has to be conciliated with a bottom-up approach, where secondary qualitative data is collected through surveys to citizens. The techniques used may undergo a pairwise comparison, a ranking assessment from 1 to 10 (or another scale), or a distribution of percentages across the various KPIs for the assignment of the weights among indicators. Citizens are different from city to city. Therefore, the weights given will vary. The weight assigned to a particular indicator depends on the relative importance of it to the citizen and local stakeholders.

Additionally, there is an intangible goal that is Inclusiveness, which is usually a very forgettable area. Smart Cities have the responsibility to overcome the challenge of dealing with inequality and social polarization [51]. The literature has been pointed at the need for actions to promote inclusion [52]. Smart Cities have to embrace inclusivity at the foreground of their agenda, to reduce social learning restrictions and social participation barriers [53]. Therefore, the city must put its efforts available to every citizen, not letting aside the disadvantaged. Smart Cities must strive open access and strategies, including the inclusion factor, to decrease the digital dividend [54].

To make sure that it is not forgotten, it shall also be made a current assessment to this aspect (since it must be a concrete goal of Smart Cities). Therefore, inclusion can be measured based on the number of people affected by the Smart City initiatives implemented. For each city would be calculated the percentages of people from each social group (or just the minorities inclusion) reached with that initiative and the final city's inclusion value will be the arithmetic mean of the results of each initiative. This will not just allow us to understand the number of the population affected but also which are the social groups that are not being taken into account.

As said before, citizens passed from a passive role through an active real on the cocreation of Smart Cities. The advances and the diffusion of mobile devices allow people to participate [55], avoiding social marginality [48], [56]. We are witnessing a change of how decision-makers include citizens into the co-creation and co-designing process. This ideology comes to oppose the risk of cities becoming ghost cities, a concept that emerged from the megalomaniac futuristic projects to create cities from scratch [57]-[59] in which citizens did not identify themselves with and therefore, abandoned cities. As soon as the city stakeholders are included in the process, higher is the chance of the city succeeds on the implementation. People have to be capable of using technology to benefit from it [60].

Several authors presented different methodological approaches to define a Smart City index and rank cities. Most of the studies in the literature used the data from the Urban Audit Perception Survey (Statistical Office of the European Union (EUROSTAT)). The indicators are usually selected by applying a hybrid research methodology, including a literature review 
and semi-structured interviews [61]. Regarding standardisation, the most common method used to normalize the gathered data is using z-transformation [62], [63] or through the minimum-maximum method on a scale of defined values [49], [64]. The experts' knowledge is used to define average weights values [49], [62], or a technical committee that considers the peculiarities of the territory in which the municipalities are located [64]. There are other options as using the Entropy Method [61] or the Analytic Hierarchy Process [65]. To accomplish the final equation is used the Multiple-Attribute Decision Making [66] or the Multi-Criteria Analysis [65].

The methodology (Fig. 2) here taken aims to achieve a final equation capable of currently assess cities taking the three aforementioned axes into account, and including the citizens in every step of the process by the allocation of the weights first of all among indicators and secondly to ponder the weight of each axis. It can be resumed as follows:

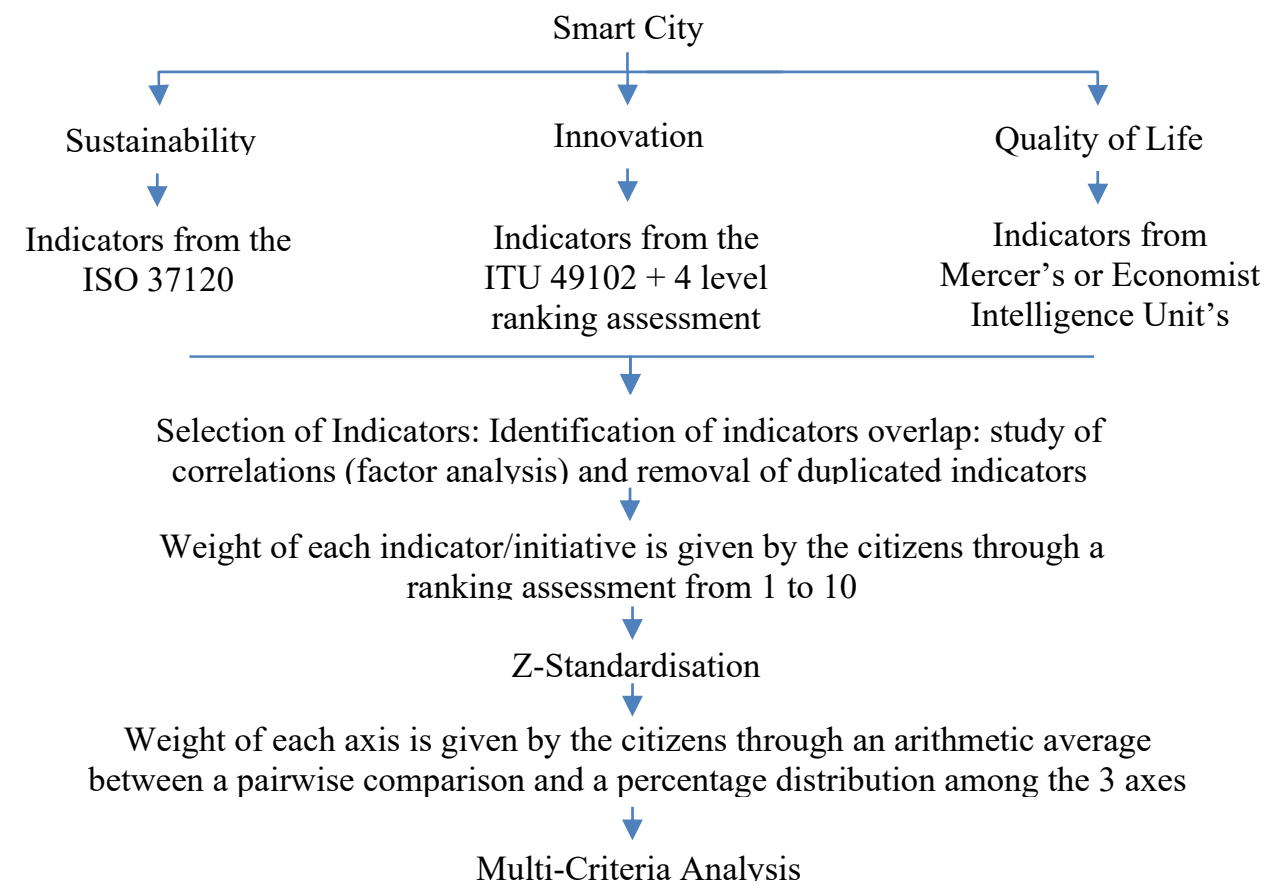

Figure 2: The methodology of the Smart City Index.

Taking the existing sets of indicators into account for each axis, it is necessary to identify which are overlapped, studying the correlation level among them and, in the end, removing the duplicated.

The success of Smart City development and assessment processes depends on the bottomup participatory approaches promoted by the city [67]. Smart Cities are not meant to be only top-down, therefore more and more, there is a need to engage citizens and other stakeholders in the co-creating and co-provision of services by a collaborative and bottom-up manner [68]. 
After the calculation of each one of the axes, as expressed in the previous section, there is a need to normalise the data. Not just vertically from all the indicators of each axis, but also horizontally among the axes of the final equation.

As mentioned before, the participation of citizens is vital to Smart Cities. The inclusion of the citizen on the Smart Cities' co-creation process on behalf of the definition of the weights. Moreover, besides the definition of the weights of all the indicators in each axis, citizens will also assign weights/coefficients to each axis in the final equation. It would be unwise to consider the same values to the coefficients of sustainability, innovation, and quality of life.

To be able to combine a standardised process with customisation, the last must be taken in the latest phase possible. In the end, the standardisation of this index will be kept until the moment it is considering the citizens' opinion to define the weights of the KPIs (customizing the index to a particular city). That is what will permit to have a global index at a local scale.

After having assigned the weights, it can be calculated the arithmetic mean [49] of each one and through a multicriteria function obtained the final result of the index.

\section{CONCLUSIONS, LIMITATIONS AND FUTURE WORK}

The Smart Cities phase we are witnessing takes citizens into the equation to co-design and co-create the cities with the decision-makers. More and more, it is important to create standardise processes so cities can have a focused approach to establish their Smart Cities strategies.

Strategically, the index here developed which contemplates three axes will be fundamental on the future establishment of a Smart Cities framework to provide a decision support tool to help cities, that are mainly in the earlies of the process of becoming a Smart City, understanding the steps they must follow to succeed.

Through the coefficients and the results obtained, policy makers can understand the profile of preferences of its citizens, allowing better planning, investment, and allocation of resources.

The index will not just only permit to have an overview about the current state of the city, but also to see what are the most critical KPIs to reach the city goals, having the chance to look for solutions capable of improving those indicators. The weights dictated by citizens should be kept unchanged over a certain period.

However, we must not forget that the approaches that are taken by comparison or ranking present ambiguities and inconsistencies. These are not easily comprehensible and informative for decision-makers or the community as a whole. These types of participatory approaches have a level of uncertainty that can be justified mostly because they are:

1. Supported by human behaviours;

2. Knowledge-dependent;

3. Result from cognitive biases.

Additionally to this limitation, it is not made a differentiation either an indicator correction based on the size of the city [69], and sustainability indicators have limitations due to the lack of systematic interactions and concrete indications on the direction to be followed [70].

Although some authors go further from the index evaluation and define a ranking among the evaluated cities, the methodology here taken does not make it possible. The coefficient of each one of the axes depends on the evaluation of citizens what will make each equation unique. Therefore, it does not make sense to compare the final result.

Dashboards and software tools can be created with this knowledge to provide cities and citizens an interface for the assessment and the analysis of the final result. There must be 
taking into account the fact that must be developed and implemented systems capable of gathering real-time data and access the historical to answer the KPIs, dealing simultaneously, with the structure of logic reasoning, the aggregation of several individual preferences and their transformation into a collective and unified result for each axis and then the calculation of the final result.

All the axes are correlated because the goals of each one of them strive to the same Smart City objectives. That can also be measured afterward to understand how the improvement of the result of a certain axis KPI can improve other axis' indicator.

\section{REFERENCES}

[1] van Bastelaer, B., Digital cities and transferability of results. Proc. 4th EDC Conf. Digit. Cities, pp. 61-70, 1998.

[2] Mahizhnan, A., Smart cities: The Singapore case. Cities, 16(1), pp. 13-18, 1999.

[3] Tan, M., Creating the digital economy: Strategies and perspectives from Singapore. Int. J. Electron. Commer., 3(3), pp. 105-122, 1999.

[4] Angelidou, M., Smart cities: A conjuncture of four forces. Cities, 47, pp. 95-106, 2015.

[5] Chourabi, H. et al., Understanding smart cities: An integrative framework. Proc. Annu. Hawaii Int. Conf. Syst. Sci., pp. 2289-2297, 2012.

[6] Anthopoulos, L.G. \& Tougountzoglou, T., Web 2.0 technologies and democratic governance: Political, policy and management implications. Web 2.0 Technol. Democr. Gov. Polit. Policy Manag. Implic., pp. 1-275, 2012.

[7] Ahvenniemi, H., Huovila, A., Pinto-Seppä, I. \& Airaksinen, M., What are the differences between sustainable and smart cities? Cities, 60, pp. 234-245, 2017.

[8] Mora, L., Bolici, R. \& Deakin, M., The first two decades of smart-city research: A bibliometric analysis. J. Urban Technol., 24(1), pp. 3-27, 2017.

[9] Bibri, S.E. \& Krogstie, J., Smart sustainable cities of the future: An extensive interdisciplinary literature review. Sustain. Cities Soc., 31, pp. 183-212, 2017.

[10] Caragliu, A., del Bo, C. \& Nijkamp, P., Smart cities in Europe. J. Urban Technol., 18(2), pp. 65-82, 2009.

[11] Piro, G., Cianci, I., Grieco, L.A., Boggia, G. \& Camarda, P., Information centric services in Smart Cities. J. Syst. Softw., 88(1), pp. 169-188, 2014.

[12] Mainka, A., Castelnovo, W., Miettinen, V., Bech-Petersen, S., Hartmann, S. \& Stock, W.G., Open innovation in smart cities: Civic participation and co-creation of public services. Proc. Assoc. Inf. Sci. Technol., 53(1), pp. 1-5, 2016.

[13] Al-Nasrawi, S., El-Zaart, A. \& Adams, C., The anatomy of smartness of smart sustainable cities: An inclusive approach. 2017 Int. Conf. Comput. Appl. ICCA 2017, pp. 348-353, 2017.

[14] Giffinger, R., Smart cities ranking of European medium-sized cities. October, 16, pp. 13-18, 2007.

[15] Ojo, A., Dzhusupova, Z. \& Curry, E., Smarter as the new urban agenda. Smarter as New Urban Agenda A Compr. View 21st Century City, 11, pp. 73-85, 2016.

[16] Marsal-Llacuna, M.L., Colomer-Llinàs, J. \& Meléndez-Frigola, J., Lessons in urban monitoring taken from sustainable and livable cities to better address the Smart Cities initiative. Technol. Forecast. Soc. Change, 90, pp. 611-622, 2015.

[17] Kitchin, R., Lauriault, T.P. \& McArdle, G., Knowing and governing cities through urban indicators, city benchmarking and real-time dashboards. Reg. Stud. Reg. Sci., 2(1), pp. 6-28, 2015.

[18] Liao, S., Chen, X., Qian, Y. \& Shen, L., Proc. 20th Int. Symp. Adv. Constr. Manag. Real Estate, pp. 575-594, 2017. 
[19] Monfaredzadeh, T. \& Berardi, U., Beneath the smart city: Dichotomy between sustainability and competitiveness. Int. J. Sustain. Build. Technol. Urban Dev., 6(3), pp. 140-156, 2015.

[20] Sharifi, A. \& Murayama, A., A critical review of seven selected neighborhood sustainability assessment tools. Environ. Impact Assess. Rev., 38, pp. 73-87, 2013.

[21] Huovila, A., Bosch, P. \& Airaksinen, M., Comparative analysis of standardized indicators for smart sustainable cities: What indicators and standards to use and when? Cities, 89, pp. 141-153, 2019.

[22] ISO, 2014. www.iso.org/obp/ui/\#iso:std:iso:37120:ed-1:en.

[23] Sharifi, A., A critical review of selected smart city assessment tools and indicator sets. J. Clean. Prod., 233, pp. 1269-1283, 2019.

[24] Stratigea, A., Leka, A. \& Panagiotopoulou, M., In search of indicators for assessing smart and sustainable cities and communities' performance. International Journal of E-Planning Research (IJEPR), 6(1), 2017.

[25] Bhattacharya, S. \& Rathi, S., Reconceptualising smart cities: A reference framework for India. Cent. Study Sci. Technol. Policy, p. 80, 2015.

[26] ITU, Recommendation ITU-T Y.4900/L.1600 overview of key performance indicators in smart sustainable cities, Itu-T Sg20, 2016.

[27] Kaika, M., "Don't call me resilient again!”: the new urban agenda as immunology ... or ... what happens when communities refuse to be vaccinated with "smart cities" and indicators. Environ. Urban., 29(1), pp. 89-102, 2017.

[28] Kramers, A., Höjer, M., Lövehagen, N. \& Wangel, J., Smart sustainable cities: Exploring ICT solutions for reduced energy use in cities. Environ. Model. Softw., 56, pp. 52-62, 2014.

[29] CEN-CENELEC-ETSI Smart and Sustainable Cities and Communities' Co-ordination Group (SSCC-CG), SSCC-CG Final report, p. 66, 2015.

[30] Akande, A., Cabral, P., Gomes, P. \& Casteleyn, S., The Lisbon ranking for smart sustainable cities in Europe. Sustain. Cities Soc., 44, pp. 475-487, 2019.

[31] Wendling, L.A., Huovila, A., zu Castell-Rüdenhausen, M., Hukkalainen, M. \& Airaksinen, M., Benchmarking nature-based solution and smart city assessment schemes against the sustainable development goal indicator framework. Front. Environ. Sci., 6, pp. 1-18, 2018.

[32] ETSI, Key performance indicators for sustainable digital multiservice cities. Int. J. Nurs. Pract., 9(6), pp. 337-337, 2017.

[33] ISO, ISO/DIS 37122 Sustainable cities and communities: Indicators for smart cities, 2018.

[34] ISO, ISO 37120:2018 Sustainable cities and communities: Indicators for city services and quality of life, 2nd ed., 2018.

[35] ITU, Recommendation ITU-T Y.4901/L.1601 gives a general guidance to cities and provides the definitions of key performance indicators (KPIs) related to the use of information and communication technology (ICT) in the context of smart sustainable cities (SSCs), 2016.

[36] ITU, Recommendation ITU-T Y.4902/L1602 on key performance indicators (KPIs) related to the sustainability impacts of information and communication technology (ICT) in smart sustainable cities, 2016.

[37] ITU, Recommendation ITU-T Y.4903/L.1603 gives general guidance to cities and provides key performance indicators (KPIs) for smart sustainable cities (SSC) to help cities achieve sustainable development goals (SDGs), pp. 1-50, 2016. 
[38] Venkat Reddy, P., Siva Krishna, A. \& Ravi Kumar, T., Study on concept of smart city and its structural components. Int. J. Civ. Eng. Technol., 8(8), pp. 101-112, 2017.

[39] Etezadzadeh, C., Smart City: Future City? Essentials, 2016.

[40] Barrionuevo, J.M., Berrone, P. \& Ricart Costa, J.E., Smart cities, sustainable progress: Opportunities for urban development. IESE Insight, 14, pp. 50-57, 2012.

[41] Debnath, A.K., Chin, H.C., Haque, M.M. \& Yuen, B., A methodological framework for benchmarking smart transport cities. Cities, 37, pp. 47-56, 2014.

[42] United Nations, UN Conference on Environment and Development, United Nations Conf. Environ. Dev. Rio Janerio, Brazil, 6, pp. 47-54, 1992.

[43] United Nations, Sustainable development goals, 2018. www.un.org/sustainabledevelopment/sustainable-development-goals.

[44] Bhattacharya, S., Patro, S.A. \& Rathi, S., Creating inclusive cities: A review of indicators for measuring sustainability for urban infrastructure in India. Environ. Urban. ASIA, 7(2), pp. 214-233, 2016.

[45] Ismagilova, E., Hughes, L., Dwivedi, Y.K. \& Raman, K.R., Smart cities: Advances in research - An information systems perspective. Int. J. Inf. Manage., 47, pp. 88-100, 2019.

[46] Tanguay, G.A., Rajaonson, J., Lefebvre, J.F. \& Lanoie, P., Measuring the sustainability of cities: An analysis of the use of local indicators. Ecol. Indic., 10(2), pp. 407-418, 2010.

[47] Mohanty, S.P., Choppali, U. \& Kougianos, E., Everything you wanted to know about smart cities. IEEE Consum. Electron. Mag., 5(3), pp. 60-70, 2016.

[48] Huston, S., Rahimzad, R. \& Parsa, A., "Smart" sustainable urban regeneration: Institutions, quality and financial innovation. Cities, 48, pp. 66-75, 2015.

[49] Lopez-Carreiro, I. \& Monzon, A., Evaluating sustainability and innovation of mobility patterns in Spanish cities: Analysis by size and urban typology. Sustain. Cities Soc., 38, pp. 684-696, 2018.

[50] Soumitra Dutta, B.L. \& Wunsch-Vincent, S. (eds), Global Innovation Index 2019, 12th ed., 2019.

[51] Hollands, R.G., Will the real smart city please stand up? Intelligent, progressive or entrepreneurial? City, 12(3), pp. 303-320, 2008.

[52] Oliveira, Á., From Smart Cities to Human Smart Cities, 2015.

[53] Silva, B.N., Khan, M. \& Han, K., Towards sustainable smart cities: A review of trends, architectures, components, and open challenges in smart cities. Sustain. Cities Soc., 38, pp. 697-713, 2018.

[54] Zygiaris, S., Smart city reference model: Assisting planners to conceptualize the building of smart city innovation ecosystems. J. Knowl. Econ., 4(2), pp. 217-231, 2013.

[55] Kirwan, C.G., Defining the middle ground: A comprehensive approach to the planning, design and implementation of smart city operating systems. Cross-Cultural Design Methods, Practice and Impact, pp. 316-327, 2015.

[56] Vanolo, A., Smartmentality: The smart city as disciplinary strategy. Urban Stud., 51(5), pp. 883-898, 2014.

[57] Carvalho, L., Smart cities from scratch? A socio-technical perspective. Cambridge J. Reg. Econ. Soc., 8(1), pp. 43-60, 2015.

[58] Reiche, D., Renewable energy policies in the Gulf countries: A case study of the carbon-neutral "Masdar City" in Abu Dhabi. Energy Policy, 38(1), pp. 378-382, 2010. 
[59] Cheng, H. \& Hu, Y., Planning for sustainability in China's urban development: Status and challenges for Dongtan eco-city project. J. Environ. Monit., 12(1), pp. 119-126, 2010.

[60] Coe, A., Paquet, G. \& Roy, J., E-governance and smart communities: A social learning challenge. Soc. Sci. Comput. Rev., 19(1), pp. 80-93, 2001.

[61] Shen, L., Huang, Z., Wong, S.W., Liao, S. \& Lou, Y., A holistic evaluation of smart city performance in the context of China. J. Clean. Prod., 200, pp. 667-679, 2018.

[62] Lazaroiu, G.C. \& Roscia, M., Definition methodology for the smart cities model. Energy, 47(1), pp. 326-332, 2012.

[63] Battarra, R., Gargiulo, C., Tremiterra, M.R. \& Zucaro, F., Smart mobility in Italian metropolitan cities: A comparative analysis through indicators and actions. Sustain. Cities Soc., 41, pp. 556-567, 2018.

[64] Dall'O, G., Bruni, E., Panza, A., Sarto, L. \& Khayatian, F., Evaluation of cities' smartness by means of indicators for small and medium cities and communities: A methodology for Northern Italy. Sustain. Cities Soc., 34, pp. 193-202, 2017.

[65] Stanković, J., Džunić, M., Džunić, Ž. \& Marinković, S., A multi-criteria evaluation of the European cities' smart performance: Economic, social and environmental aspects. Zb. Rad. Ekon. Fak. u Rijeci časopis za Ekon. Teor. i praksu / Proc. Rijeka Fac. Econ. J. Econ. Bus., 35(2), pp. 519-550, 2017.

[66] Escolar, S., Villanueva, F.J., Santofimia, M.J., Villa, D., del Toro, X. \& López, J.C., A multiple-attribute decision making-based approach for smart city rankings design. Technol. Forecast. Soc. Change, 142, pp. 42-55, 2018.

[67] Hemment, D., Woods, M., Appadoo, V. \& Bui, L., Community Key Performance Indicators (Community KPIs) for the IoT and Smart Cities, 2016.

[68] BSI, Smart city service framework: Guide customer to establishing strategies for smart cities and communities. BSI Stand. Publ., 2014.

[69] Borsekova, K., Koróny, S., Vaňová, A. \& Vitálišová, K., Functionality between the size and indicators of smart cities: A research challenge with policy implications. Cities, 78, pp. 17-26, 2018.

[70] Huang, S.L., Yeh, C.T., Budd, W.W. \& Chen, L.L., A sensitivity model (SM) approach to analyze urban development in Taiwan based on sustainability indicators. Environ. Impact Assess. Rev., 29(2), pp. 116-125, 2009. 